\title{
Glutathione and GSH-dependent enzymes in patients with liver cirrhosis and hepatocellular carcinoma
}

\author{
Hanna Czeczot ${ }^{\bowtie}$, Dorota Ścibior, Michał Skrzycki and Małgorzata Podsiad \\ Chair and Department of Biochemistry, Medical University of Warsaw, Warszawa, Poland \\ ®e-mail: hanna.czeczot@wp.pl
}

Received: 23 June, 2005; revised: 18 October, 2005; accepted: 16 December, 2005

available on-line: 09 January, 2006

\begin{abstract}
We investigated glutathione level, activities of selenium independent GSH peroxidase, selenium dependent GSH peroxidase, GSH S-transferase, GSH reductase and the rate of lipid peroxidation expressed as the level of malondialdehyde in liver tissues obtained from patients diagnosed with cirrhosis or hepatocellular carcinoma. GSH level was found to be lower in malignant tissues compared to adjacent normal tissues and it was higher in cancer than in cirrhotic tissue. Non-SeGSH-Px activity was lower in cancer tissue compared with adjacent normal liver or cirrhotic tissue, while Se-GSH-Px activity in cancer was found to be similar to its activity in cirrhotic tissue and lower compared to control tissue. An increase in GST activity was observed in cirrhotic tissue compared with cancer tissue, whereas the GST activity in cancer was lower than in adjacent normal tissue. The activity of GSH-R was similar in cirrhotic and cancer tissues, but higher in cancer tissue compared to control liver tissue. An increased level of MDA was found in cancer tissue in comparison with control tissue, besides its level was higher in cancer tissue than in cirrhotic tissue. Our results show that the antioxidant system of cirrhosis and hepatocellular carcinoma is severely impaired. This is associated with changes of glutathione level and activities of GSH-dependent enzymes in liver tissue. GSH and enzymes cooperating with it are important factors in the process of liver diseases development.
\end{abstract}

Keywords: hepatocellular carcinoma, liver cirrhosis, glutathione, glutathione peroxidase, glutathione reductase, glutathione S-transferase, malondialdehyde

Cirrhosis, which results from damage to liver cells from toxins, inflammation (viral or parasitic), metabolic derangements and other chronic liver diseases, such as hemochromatosis, can lead to an inability of the liver to perform its biochemical functions. It is most commonly caused by long-lasting alcohol abuse or infection with hepatitis $B$ virus and hepatitis C virus (Piekarska \& Matusiak, 2004; Lotersztajn et al., 2005; Rehermann \& Nascimbeni, 2005).

Hepatocellular carcinoma is a type of cancer that arises from hepatocytes, the major cell type of the liver. Worldwide it is considered the number one or number two cause of cancer death. Chronic infection with $\mathrm{HBV}$ and $\mathrm{HCV}$ also increases the risk of developing hepatocellular carcinoma. About 80\% of people with hepatocellular carcinomas have cirrhosis (Kamel \& Bluemke, 2002). The liver is a common site of metastases from a variety of organs such as lung, breast, colon and rectum (Badvie, 2000; Ahn \& Flamm, 2004; Voigt, 2005).

Both liver cirrhosis and hepatocellular cancer formation are multifactorial processes and possible mechanisms leading to those diseases have not been clarified yet. Increasing evidence points to free radical damage as an important contributor to the diseases. Metabolism of various endo- and exogenous compounds and viruses generates reactive oxygen species, which could be involved in the pathogene-

Abbreviations: GSH, reduced glutathione; GSH-Px, glutathione peroxidase; GSH-R, glutathione reductase; GSSG, oxidized glutathione; GST, glutathione S-transferase; HBV, hepatitis B virus; HCV, hepatitis C virus; MDA, malondialdehyde; ROS, reactive oxygen species; Se-GSH-Px, non-Se-GSH-Px, selenium independent glutathione peroxidase; selenium dependent glutathione peroxidase; TBARS, thiobarbituric acid-reactive substances. 
sis of different liver diseases, including cirrhosis and hepatocellular cancer (Dreher \& Junod, 1996; Jungst et al., 2004; Balasubramanian \& Kowdley, 2005).

Many reports indicate that GSH and enzymes cooperating with it are important in neoplastic diseases and play crucial role in the defence against reactive oxygen species (Oberley \& Oberley, 1997; Gate et al., 1999; Abou Ghalia \& Fouad, 2000).

Cellular glutathione and related enzymes such as glutathione peroxidase, glutathione $S$-transferase and glutathione reductase are among the principal protective mechanisms against endogenous and exogenous toxic substances and free radicals-mediated damage in liver tissue as well as in other tissues (Murthy et al., 1992; Peng et al., 1998; Hayes \& McLellan, 1999).

Formation of ROS is a normal consequence of a variety of essential biochemical processes. It is also known that oxygen radicals may be formed in excess in chronic diseases of the gastrointestinal tract. The main source of oxidants in the liver are probably phagocytes and inflammatory state mediators, which are present in the tissue of patients with liver diseases and could generate oxidants upon activation, which might contribute to the increased risk of cancer (Szatrowski \& Nathan, 1991).

Oxygen radical production, which increases with clinical progression of diseases, involves increased lipid peroxidation. The process of lipid peroxidation consist in oxidative conversion of polyunsaturated fatty acids to products known as malondialdehyde or lipid peroxides, which is the most studied, biologically relevant, free radical reaction. MDA itself, owing to its high cytotoxicity and inhibitory action on protective enzymes, is suggested to act as a tumor promoter and co-carcinogenic agent. On the other hand, it is reported that lipid hydroperoxides decompose to yield reactive aldehydes, such as MDA and 4-hydroxynonenal. MDA is a well-characterised mutagen that reacts with deoxyguanosine to form a major endogenous adduct found in the DNA of human liver (Marnett, 1999; Mylonas \& Kouritas, 1999).

On the basis of experimental models it has been proposed that oxidative stress may lead to neoplastic transformation. Therefore, the occurrence of primary hepatic cancer in the course of cirrhosis of $\mathrm{HBV}, \mathrm{HCV}$ or other etiology may be associated with disturbances of the antioxidant barrier of the organism (Chrobot et al., 2000).

The aim of this work was to evaluate glutathione level, activities of GSH-dependent antioxidant enzymes and the level of MDA in tissues obtained from patients with liver cirrhosis or hepatocellular carcinoma.

\section{MATERIALS AND METHODS}

Patients. Materials for this study were obtained from patients with liver cirrhosis or hepatocellular carcinoma diagnosed by routine histopathological examination. The patients were hospitalised in the Department of General and Transplantation Surgery, Medical University of Warsaw (from 2002 to 2003). None of them had received preoperative radiotherapy or chemotherapy. Cirrhotic tissues were obtained at the time of surgery from 15 patients with liver cirrhosis $(7$ females and 8 males, medium age 39, range 25-56). Most of tested patients were above 50 years old). Liver cancer and normal adjacent tissues were taken from 15 patients with preliminary hepatocellular carcinoma (5 females and 10 males, median age 58, range 44-67).

Studies were approved by the Bioethics Committee of the Medical University of Warsaw (Poland).

Tissues preparation. Immediately after surgical removal, the resected cirrhotic, tumour and control tissue were washed in $0.9 \% \mathrm{NaCl}$ and frozen at $-80^{\circ} \mathrm{C}$. The frozen tissues were cut into small pieces and homogenized on ice in $10 \mathrm{vol}$. of $50 \mathrm{mmol} / \mathrm{l}$ Tris/ $\mathrm{HCl}$ buffer ( $\mathrm{pH} 7.5$ ) containing $1 \mathrm{mmol} / 1 \mathrm{MnCl}_{2}$, $0.2 \mathrm{~mol} / \mathrm{l} \mathrm{KCl}$ and $0.1 \%(\mathrm{v} / \mathrm{v})$ Triton X-100 using a Heidolph Diax 900 blender at low speed, five times for 2-min periods at 3-min intervals. After $30 \mathrm{~min}$ extraction on a magnetic stirrer, the homogenates were centrifuged at $12000 \times g$ for $30 \mathrm{~min}$ at $4^{\circ} \mathrm{C}$. The supernatants obtained were used for determination of glutathione and glutathione-dependent enzyme activities.

Glutathione measurement. Reduced glutathione level was measured in tissues as described by Sedlak and Lindsay (1968) and Snel et al. (1993). GSH was expressed as $\mu$ mole/mg protein.

\section{Measurement of enzyme activities}

Glutathione peroxidases activities. Measurement of GSH-Px activities were based on the methods described by Paglia and Valentine (1967) and Wendel (1981). GSH-Px catalyzes the oxidation of glutathione by cumene hydroperoxide (for selenium independent glutathione peroxidase, EC 1.11.1.7) or hydrogen peroxide (for selenium-dependent peroxidase, EC 1.11.1.9).

Glutathione reductase (EC 1.6.4.2) activity. GSH-R activity was assayed by using oxidized glutathione as a substrate according to the method described by Goldberg and Spooner (1987).

Glutathione transferase (EC 2.5.1.18) activity. GST activity was measured according to the method of Habig et al. (1974) using chlorodinitrobenzene $(\mathrm{CDNB})$ as a substrate. 
The activities of enzymes in tissues were expressed as $\mu$ mole/min per mg protein.

Lipid peroxidation - malondialdehyde measurement. MDA was determined by spectrophotometry of the coloured product of the thiobarbituric acid-reactive substances complex (Ohkawa et al., 1968). Total TBARS were expressed as MDA. Results were expressed as nmole of MDA per mg protein.

Protein measurement. Total protein was measured in all samples by Bradford procedure (1976), using bovine serum albumin as a standard.

Statistical analysis. All data are expressed as mean \pm S.D. Mean values were assessed for significance by Student's $t$-test at $P<0.05$. Statistical analysis was performed with the STATISTICA programme, version 6 .

\section{RESULTS}

Glutathione level and glutathione peroxidases, glutathione reductase and glutathione $S$-transferase activities were determined in cirrhotic tissues from 15 patients and in cancer and adjacent healthy tissues from 15 patients with hepatocellular carcinoma. MDA level, as a secondary product of lipid peroxidation, was also measured in those tissues.

Results are summarised in Table 1. They are expressed as mean \pm S.D.

Data in Table 1 show that mean glutathione level was lower in cancer tissues as compared to adjacent normal tissues and its level in liver cirrhotic tissue was found to be significantly lower $(P<0.05)$ from its level in cancer tissue.

Non-Se-GSH-Px activity was significantly lower in cancer tissue compared with adjacent normal liver tissues and cirrhotic tissue. Se-GSH-Px activity in cancer tissues was found to be significantly lower compared to control liver tissue, whereas differences in Se-GSH-Px activity between cancer and cirrhotic tissue were nonsignificant (Table 1).
We observed a significantly higher GST activity in cirrhotic tissue as compared with cancer tissue, whereas its activity in cancer tissue was lower than in adjacent healthy liver (Table 1).

We demonstrated that the activity of GSH-R was similar in cirrhotic and cancer tissues. It was significantly higher in cancer tissue compared to control liver (Table 1).

A comparison of MDA level in supernatants prepared from cirrhotic, cancer and adjacent normal liver tissues indicated a higher MDA content in cancer tissue compared to control tissue or cirrhotic tissue $(P<0.05)$ (Table 1$)$.

\section{DISCUSSION}

The intracellular concentration of ROS is tightly regulated by multiple defence mechanisms involving ROS scavenging enzymes and small antioxidant molecules. Among these antioxidant systems acting as antioxidants or scavengers are glutathione and GSH-dependent enzymes, which are one of the protective mechanism vs oxidative damage, both in the circulation and in various tissues, including liver (Gate et al., 1999; Sies, 1999). A wide variety of oxidising molecules such as ROS and/or depleting agents can alter the glutathione redox state, which is normally maintained by the activity of GSH-depleting (GSH-Px, GST) and GSH-replenishing (GSHR) enzymes (Halliwell \& Gutteridge, 1996; Hayes \& McLellan, 1999).

In the present study we determined the reduced glutathione level and non-Se-GSH-Px, SeGSH-Px, GSH-R and GST activities in extracts prepared from normal, cirrhotic and cancer liver tissues. We also determined the level of malondialdehyde as a final product of lipid peroxidation.

This study confirms a decrease of the GSH level in cirrhotic and cancer tissue compared to healthy liver tissue. GSH homeostasis at the cellular

Table 1. Glutathione and malondialdehyde level and activities of GSH-dependent enzymes in liver cirrhosis, hepatocellular carcinoma and adjacent normal liver tissue

\begin{tabular}{llll}
\hline Level/activity & Cirrhosis & Hepatocellular carcinoma & Healthy liver \\
\hline GSH $\mu$ mole/mg protein & $3.45 \pm 2.11$ & $4.62 \pm 2.94 * / * *$ & $5.52 \pm 3.27$ \\
MDA nmole/mg protein & $0.102 \pm 0.036$ & $0.154 \pm 0.06^{*} / * *$ & $0.087 \pm 0.038$ \\
Non-Se-GSH-Px $\mu$ mole/min per mg protein & $0.074 \pm 0.039$ & $0.045 \pm 0.021^{* * *}$ & $0.062 \pm 0.02$ \\
Se-GSH-Px $\mu$ mole/min per mg protein & $0.023 \pm 0.008$ & $0.021 \pm 0.009 *$ & $0.031 \pm 0.015$ \\
GST $\mu$ mole/min per mg protein & $0.047 \pm 0.023$ & $0.019 \pm 0.012^{* * *}$ & $0.03 \pm 0.013$ \\
GSH-R $\mu$ mole/min per mg protein & $0.049 \pm 0.024$ & $0.05 \pm 0.019^{*}$ & $0.037 \pm 0.017$ \\
\hline
\end{tabular}

${ }^{*} P<0.05$ compared to control tissue (adjacent normal liver tissue), ${ }^{* *} P<0.05$ compared to cirrhotic tissue. 
level is maintained by the balance between biosynthesis, uptake, oxidation and export. Its decrease in cirrhotic and cancer tissues is probably related to a reduced synthesis of the tripeptide by the diseased liver. This alteration may influence the capability of the liver to provide protection against oxidative damage (Dalhoff et al., 1992; Logurcio \& Di Pierro, 1999; Fernandez-Checa \& Kaplowitz, 2005).

The low GSH level may also be associated with an increase of production of reactive oxygen species and free radicals in cirrhotic and liver cancer tissues. These ROS may be actively scavenged by GSH, resulting in the formation of the oxidized form of GSH (GSSG). This oxidized form is rapidly converted to GSH by GSH reductase (Kikkawa et al., 1992). In our study we observed an increase of GSH$\mathrm{R}$ activity in cirrhosis and hepatocellular carcinoma compared to control tissue.

The decrease of GSH level in cirrhotic tissue may be connected with the increase of non-Se-GSHPx and GST activities in this tissue, which might result from elevated concentrations of $\mathrm{O}_{2}^{-}$radicals, $\mathrm{H}_{2} \mathrm{O}_{2}$ and lipid peroxides (Fisher et al., 1999). A greatly increased production of reactive oxygen metabolites might overpower the capacity of the tissue to synthesize or regenerate sufficient amounts of GSH, resulting in a decrease in tissue GSH concentration (Matiushin et al., 1998).

GST catalyses the conjugation of reduced glutathione with a wide spectrum of electrophiles and is considered to an important component of the detoxification system. It also catalyses a peroxidative reaction with the production of GSSG. The ability of GST to alter the level of intracellular GSH in the liver in response to generation of ROS has been implicated in protection of cells against free-radicals inducting agents (Sherman et al., 1983; Tsuchida \& Sato, 1992; Tew \& Ronai, 1999).

The liver is the main organ in the metabolism and homeostasis of selenium in the body, because selenoproteins, including Se-GSH-Px, are predominantly synthesised and secreted by the liver (Ursini \& Bindoli, 1987; Buljevac et al., 1996; Czuczejko et al., 2002; Chu et al., 2004). We observed a decrease of Se-GSH-Px activity in cirrhotic and liver cancer tissues compared with adjacent normal liver.

A decrease in GSH concentration in cirrhotic and cancer tissues might cause the effectiveness of non-Se-GSH-Px activity to be restricted, as manifested by the intensification of lipid peroxidation and the increased level of final products of their peroxidation. That lipid peroxidation was enhanced during cancer development was manifested in a significant increase in malondialdehyde level. It has been claimed that MDA acts as a tumor promoter and co-carcinogenic agent because of its high cytotoxicity and inhibitory action on protective enzymes (Marnett, 1999; Mylonas \& Kouritas, 1999).

In this study we found an increase of MDA levels in cirrhotic and cancer tissue compared with control liver tissue. The obtained results indicate significant changes in the antioxidant capacity of hepatocellular cancer tissue which lead to enhanced action of oxygen radicals, resulting in lipid peroxidation.

The obtained results agree with other studies which have shown decreased GSH content, increased MDA level and changes in activities of GSH related enzymes (Casaril et al., 1985; 1994; Corrocher et al., 1986; Skrzydlewska et al., 2003).

Our findings indicate that the glutathione antioxidant system in cirrhosis and hepatocellular carcinoma is imbalanced and support the hypothesis that oxidative stress plays an important role in the development of those liver diseases. One critical question is whether this abnormality is one of the causes of those liver diseases or is just one of the consequences of their progression. This question remains to be answered by additional research.

In summary, our results show that the antioxidant potential in cirrhosis and hepatocellular carcinoma is unbalanced which leads to an increase in reactive oxygen species action. In cirrhotic and cancer tissues the GSH level is decreased, the MDA level is increased and GSH-dependent enzyme activities are elevated.

The decreased ability to remove reactive oxygen species and free radicals from tissues is one of the factors which may further result in the development of neoplasia.

\section{Acknowledgements}

This work was financed by a grant from the Medical University in Warsaw No. 1WK/W2/2004.

\section{REFERENCES}

Abou Ghalia AH, Fouad IM (2000) Clin Biochem 33: 657662.

Ahn J, Flamm SL (2004) Dis Monitor 50: 556-573.

Badvie S (2000) Postgrad Med J 76: 4-11.

Balasubramanian S, Kowdley KV (2005) Clin Liver Dis 9: 83-101.

Bradford MM (1976) Anal Biochem 72: 248-254.

Buljevac M, Romic Z, Vucelic B, Banic M, Krznaric Z, Plesko S (1996) Acta Med Croatica 50: 11-14.

Casaril M, Gabrielli GB, Dusi S, Nicoli N, Bellisola G, Corrocher R (1985) Eur J Cancer Clin Oncol 21: 941-944.

Casaril M, Corso F, Bassi A, Capra F, Gabrielli GB, Stanzial AM, Nicoli N, Corrocher R (1994) Int J Clin Lab Res 24: 94-97.

Chrobot AM, Szaflarska-Szczepanik A, Drewa G (2000) Med Sci Monit 6: 713-718. 
Chu FF, Esworthy RS, Doroshow JH (2004) Free Radic Biol Med 36: 1481-1495.

Corrocher R, Casaril M, Bellisola G, Gavarielli GB, Nicoli N, Guidi GC, De Sandre G (1986) Cancer 15: 16581662.

Czuczejko J, Halota W, Zachara BA, Staubach-Topczewska E (2002) Pol Merk Lek 13: 312-315.

Dalhoff K, Ranek L, Mantoni M, Poulsen HE (1992) Liver 12: 341-343.

Dreher D, Junod AF (1996) Eur J Cancer 32A: 30-38.

Fernandez-Checa JC, Kaplowitz N (2005) Toxicol Appl Pharmacol 204: 263-273.

Fisher AB, Dodia C, Manevich Y, Chen JW, Feinstein SI (1999) J Biol Chem 274: 21326-21334.

Gate L, Paul J, Nguyen BA, Tew KD, Tapiero H (1999) Biomed Pharmacother 53: 169-180.

Golberg DM, Spooner RJ (1987) In Methods of Enzymatic Analysis (Bregmayer HV, ed) pp 258-265, Verlag Chemie.

Habig WH, Pabst M, Jacoby W (1974) J Biol Chem 249: 7130-7139.

Halliwell B, Gutteridge JMC (1996) Arch Biochem Biophys 280: $1-8$.

Hayes JD, McLellan LI (1999) Free Radic Res 31: 273-300.

Jungst C, Cheng B, Gehrke R, Schmitz V, Nischalke HD, Ramakers J, Schramel P, Schirmacher P, Sauerbruch T, Caselmann WH (2004) Hepatology 39: 1663-1672.

Kamel IR, Bluemke DA (2002) J Vasc Intervent Radiol 13: 173-184.

Kikkawa S, Kadohara M, Kawasaki H (1992) Res Commun Chem Pathol Pharmacol 78: 289-309.

Loguercio C, Di Pierro M (1999) Ital J Gastroenterol Hepatol 31: 401-407.

Lotersztajn S, Julien B, Teixeira-Clerc F, Grenard P, Mallat A (2005) Annu Rev Pharmacol Toxicol 45: 605-628.
Marnett LJ (1999) Mutat Res 424: 83-95.

Matiushin BN, Loginov AS, Tkachev VD (1998) Klein Lab Diagn 4: 16-8.

Murphy ME, Scholich H, Sies H (1992) Eur J Biochem 210: 139-146.

Mylonas C, Kouritas D (1999) In Vivo 13: 295-309.

Oberley TD, Oberley LW (1997) Histol Histhopathol 12: 525535.

Ohkawa H, Ohishi N, Yagi K (1968) Anal Biochem 25: 192205.

Paglia D, Valentine W (1967) J Lab Clin Med 70: 158-168.

Peng RX, Wang H, Wang YS, Fu LS, Ding H (1998) Zhongguo Yao Li Xue Bao 19: 167-171.

Piekarska A, Matusiak K (2004) Pol Arch Med Wewn 111: 397-403.

Rehermann B, Nascimbeni M (2005) Nat Rev Immunol 5: 215-229.

Sedlak J, Lindsay RH (1968) Anal Biochem 25: 192-205.

Sherman M, Campbell JA, Titmuss SA, Kew MC, Kirsch RE (1983) Hepatology 3: 170-176.

Sies H (1999) Free Radic Biol Med 27: 916-921.

Skrzydlewska E, Kożusko B, Sulkowska M, Bogdan Z, Kozłowski M, Snarska J, Puchalski Z, Sulkowski S, Skrzydlewski Z (2003) Hepatogastroenterology 50: 126131.

Snel CAW, Zhao Y, Mulder GJ, Pang KS (1993) Anal Biochem 212: 28-34.

Szatrowski TP, Nathan CF (1991) Cancer Res 51: 794-798.

Tew KD, Ronai Z (1999) Drug Resist Updat 2: 143-147.

Tsuchida S, Sato K (1992) Crit Rev Biochem Mol Biol 27: 337-384.

Ursini F, Bindoli A (1987) Chem Phys Lipids 44: 255-276.

Voigt MD (2005) Clin Liver Dis 9: 151-169.

Wendel A (1981) Methods Enzymol 77: 325-333. 